\title{
Patient involvement to inform the design of a clinical trial in postbariatric hypoglycaemia
}

\author{
Matthias Hepprich ${ }^{1,2^{*}} \mathbb{D}$, Marc Y. Donath ${ }^{1}$ and Lars G. Hemkens $3,4,5$
}

\begin{abstract}
Background: Bariatric surgery may lead to symptomatic postprandial hypoglycaemia as a major side effect without established therapy so far. We aimed to develop an evidence-based study design of a clinical trial that tests treatment options and can provide useful patient-relevant evidence.

Methods: We searched systematically for guidance of core outcome sets to determine the most relevant types of outcomes and duration of such a trial. Our search comprised literature databases, a database of core outcome sets and self-help organizations. We then developed a simple online questionnaire based on interviews with Germanspeaking patients with postprandial hypoglycaemia after bariatric surgery. We recruited participants by reaching out to all German speaking endocrinologists in Switzerland and large Swiss bariatric centres. We asked for preferences regarding outcome types and acceptable duration of being included in a corresponding clinical trial.
\end{abstract}

Results: The literature search did not identify evidence-based guidance for informing our study design. Experience of clinical and research routine as well as patient interviews helped in identifying potential outcomes and the design of an online questionnaire. Therein, a total of 29 persons started the questionnaire and 22 answered questions related to the primary outcome. Of these, 17 (77.3\%) deemed quality of life more relevant as primary outcome than the rate of hypoglycaemic episodes. A trial length of four weeks or longer was regarded as acceptable for 19 of 21 respondents to this question (91.4\%) and of six months or longer for 12 respondents (56\%).

Conclusions: In situations with no other guidance, a simple questionnaire may help to inform trial design decisions. This study identifies a patient preference for "quality of life" as a primary outcome and supports the evidence-based conception of a patient-centred clinical trial in postbariatric hypoglycaemia.

Keywords: Patient involvement, Postprandial hypoglycaemia, Late-dumping, Bariatric surgery, Outcome finding

\section{Background}

Bariatric surgery is one of the most effective interventions to achieve long-term weight loss in patients with severe obesity, but frequently leads to serious side effects [1-3]. One of them is postprandial hypoglycaemia (PBH),

\footnotetext{
*Correspondence: matthias.hepprich@usb.ch

'Division of Endocrinology, Diabetology and Metabolism, University Hospital Basel, Petersgraben 4, 4053 Basel, Switzerland

${ }^{2}$ Clinic of Endocrinology, Cantonal Hospital Olten, Basler Strasse 150, 4600 Olten, Switzerland

Full list of author information is available at the end of the article
}

previously referred to as late-dumping, affecting in standardized test settings about $50 \%$ of patients with a gastric bypass [4-6] although it is frequently undiagnosed [7]. This may lead to a reduced quality of life [8], secondary weight gain $[9,10]$ and may even be associated with an increased mortality [11-13]. Serious hypoglycaemia requiring assistance of third parties and/or hospitalization for hypoglycaemia affects around $1 \%[8,14]$. Although some patients are able to effectively control hypoglycaemic episodes with dietary modification, there is no established

(c) The Author(s). 2020 Open Access This article is licensed under a Creative Commons Attribution 4.0 International License, which permits use, sharing, adaptation, distribution and reproduction in any medium or format, as long as you give appropriate credit to the original author(s) and the source, provide a link to the Creative Commons licence, and indicate if changes were made. The images or other third party material in this article are included in the article's Creative Commons licence, unless indicated otherwise in a credit line to the material. If material is not included in the article's Creative Commons licence and your intended use is not permitted by statutory regulation or exceeds the permitted use, you will need to obtain permission directly from the copyright holder. To view a copy of this licence, visit http://creativecommons.org/licenses/by/4.0/ The Creative Commons Public Domain Dedication waiver (http://creativecommons.org/publicdomain/zero/1.0/) applies to the data made available in this article, unless otherwise stated in a credit line to the data. 
treatment for severely affected patients with frequent postprandial hypoglycaemia [5].

A recent exploratory trial with 12 patients after gastric bypass indicated that both the SGLT2-inhibitor empagliflozin and the IL-1 receptor antagonist anakinra may reduce postprandial insulin release and prevents hypoglycaemia [15]. These findings call for further evaluation in a larger randomized clinical trial.

We aimed to develop an evidence-based study design for such a trial that tests these treatment options and can provide useful patient-relevant evidence on their merits. However, selecting a primary outcome that appropriately reflects the needs of patients turned out to be a major challenge. Ideally, such a trial would explore patient-relevant outcomes but also improve the understanding of the underlying metabolic effects of the tested treatments that would mediate potential patient-centred benefits (such as glucose levels).

Clear frameworks such as those established for assessment of anti-diabetic treatments that may help to utilize hypoglycaemia as trial outcome in non-diabetic persons are lacking. Extrapolation of such frameworks to nondiabetic patients may be inappropriate and would require strong assumptions as changing glucose levels in diabetic and nondiabetic persons may correspond to different symptoms and health effects.

For postprandial hypoglycaemia, no core outcome set (COS), as "an agreed standard set of outcomes that should be measured and reported, as a minimum, in all clinical trials in specific areas of health or healthcare" [16] has been published. In 2016, the BARIAtric and metabolic surgery Clinical Trials (BARIACT) project defined $\mathrm{COS}$ for patients undergoing bariatric surgery based on patient and healthcare provider perspectives. However, postprandial hypoglycaemia was not among the list of candidate outcomes included in the delphi processes [17].

We performed a thorough literature search in September 2019 for clinical trials specifically including patients with symptomatic postprandial hypoglycaemia and found only small trials using biomarkers (e. g. time of glucose levels below a specific threshold) $[18,19]$ or clinical scoring systems (e. g. Edinburgh Hypoglycaemia Scale) mostly within standardized mixed meal testsettings [20-22] which do not reflect real-life circumstances and provide no patient-relevant information. Only one trial that we identified reported effects on quality of life as a secondary outcome [23].

The measurement of hypoglycaemic episodes by continuous glucose measurement systems appears to accurately depict real-life glucose level variation and may give an objective measurement of the metabolic effects of an intervention aiming to alleviate symptomatic metabolic disorders [24]. However, it is unclear how relevant it is for patients with symptomatic hypoglycaemic episodes to measure merely metabolic changes, since some hypoglycaemic episodes may not be recognized [7, 25, 26] and have varying symptomatic presentation, especially when occurring frequently or during the night [7]. Measuring the frequency of hypoglycaemic episodes alone without consideration of their severity and patient-reported symptoms, seems inadequate to reflect patients' needs. Furthermore, using the classical Whipple's triad (i.e. appearance of typical symptoms, low plasma glucose, and relief of symptoms following glucose administration) would be unfeasible in a real-life evaluation. We, therefore, sought to identify the outcome parameter that is most relevant for patients and their subjective wellbeing.

\section{Methods}

The aim of this project was to develop an evidencebased study design of a clinical trial that tests treatment options and can provide useful patient-relevant evidence.

First, we searched published articles that might address outcomes for clinical trials on postbariatric hypoglycaemia to identify outcome domains and to obtain a list of potential core outcome domains [27] with searches on PubMed using terms related to bariatric surgery and hypoglycaemia (we searched first in September 2019 and searched again in July 2020; the detailed search strategy is in the Appendix). as well as COMET initiative database (http://www.comet-initiative.org/studies/), and Google scholar using the terms "patient-relevant outcome" or "patient-centered outcome" combined with "bariatric surgery", "gastric bypass", "sleeve gastrectomy", "late-dumping" or "postprandial hypoglycaemia" excluding articles with the term "diabetes".

Second, we set out to identify specific self-help organizations for patients with postbariatric hypoglycaemia in Switzerland using a google and facebook search with the German terms for "self-help organization" and "bariatric surgery" or "bypass" and "late-dumping" or "hypoglycaemia".

Third, we approached the patients in our clinic and the Hypo-BEAR trial participants [15] to collect in unstructured discussions with individual patients any potential patient-relevant outcome measures with various aspects of daily life that would be affected by hypoglycemic episodes (s. supplements, preliminary questionnaire). We then presented to two of the most severely affected patients in our clinic with postprandial hypoglycaemia who agreed to support us for this project with their patient feedback to rank each item from 0 (not important at all) to 10 (very important).

Fourth, we developed an anonymous limesurvey online questionnaire in German on the basis of the previous findings that quality of life and a reduction of 
hypoglycaemia would be the most relevant outcome domains (s. supplements, short questionnaire [28]).

With this approach, we aimed to prioritize the outcome candiates, according to patients' preferences and values, and then determine the study duration and follow-up. The questionnaire contained a brief outline of the nature of the study, that persons with confirmed postprandial hypoglycaemia after bariatric surgery can participate and that it is entirely voluntary. The data items and corresponding questions are listed in Tables 2 and 3. On 25 October 2019, the questionnaire was sent via email to all German speaking endocrinologists by the Swiss Society of Endocrinology and Diabetes as well as directly by the study team to large bariatric centres in the German-speaking part of Switzerland (Clarunis Centre for Gastrointestinal and Liver Diseases, St. Clara Hospital and University Hospital, Basel; Cantonal Hospital Aarau; Cantonal Hospital Solothurn Site Olten and Site Solothurn; Centre of Bariatric Surgery, Bern). The healthcare providers then asked their patients to fill out an online version of the questionnaire. Where this was not possible we provided them with a printed version, that could be filled out by hand and was later digitized by our study team.

\section{Statistical analysis}

All analyses were descriptive. We calculated medians and interquartile ranges unless stated otherwise.

\section{Ethics and transparency}

The study was conducted in compliance with the current version of the Declaration of Helsinki, the ICHGCP or ISO EN 14155 as well as national legal and regulatory requirements and approved by the local ethics committee (EKNZ Req-2019-00933). All data and material are available online in the Open Science Framework under https://doi.org/10.17605/OSF.IO/49RDE.

\section{Results}

The search in PubMed yielded 521 hits, none of them were deemed relevant after screening titles and abstracts (Table 1). The free-text search in Google Scholar and the search on the COMET database also retrieved no pertinent information. We identified two main organizations dealing with bariatric patients - the Swiss Obesity Foundation [29] and the Swiss Bariatric Surgery Selfhelp Network [30]. Both online plattforms offered contact details to various self-help organizations within Switzerland. None spefically addressed a subgroup for postbariatric hypoglycaemia. Also the internet forum of the Swiss bariatric surgery self-help network did not yield results for "late-dumping" or "hypoglycaemia" nor was it possible to identify a spokesperson for respective patients.

The two severely affected patients directly providing feedback on the list of outcomes resulting from discussions with other patients valued almost all outcome parameters as important. These data confirmed our expectation that more global outcome domains would be preferable. Similar to trials in oncology [31] and as part of the COS of the BARIACT project [17], we selected "quality of life" as one patient-relevant outcome parameter that would encompass multiple identified items. As our second potential outcome, we chose a reduced rate of hypoglycaemic episodes. Both reliably measurable by validated instruments such as questionnaires [8] or continuous glucose monitoring systems respectively [24].

The online questionnaire was active from 8 October 2019 to 26 February 2020. 29 persons accessed the online questionnaire website, 22 responded to the question

Table 1 Study flow listing applied methods with date, findings and respective results

\begin{tabular}{|c|c|c|c|}
\hline Method & Date & Findings & Results \\
\hline \multicolumn{4}{|l|}{ Literature search } \\
\hline PubMed & $\begin{array}{l}09 / 2019 \\
06 / 2020\end{array}$ & 521 titles/abstracts (last search) & no pertinent articles \\
\hline Google scholar & 09/2019 & 278 titles/abstracts & \\
\hline COMET database & 09/2019 & 0 hits & \\
\hline $\begin{array}{l}\text { Search for patient organizations } \\
\text { in } \mathrm{CH}\end{array}$ & 09/2019 & $\begin{array}{l}\text { Swiss Self-help Organization for } \\
\text { Bariatric Surgery (www.shg-bern.ch) } \\
\text { Swiss Obesity Foundation with } \\
23 \text { self-help organizations } \\
\text { (www.saps.ch) }\end{array}$ & $\begin{array}{l}\text { no specific groups or spokesperson } \\
\text { on web-plattform and forum for PBH } \\
\text { no specific groups or spokesperson } \\
\text { for PBH }\end{array}$ \\
\hline $\begin{array}{l}\text { Potential outcome collection by } \\
\text { clinical and research experience }\end{array}$ & 10/2019 & 13 potential outcome parameters & $\begin{array}{l}\text { design of a preliminary questionnaire } \\
\text { s. supplements }\end{array}$ \\
\hline $\begin{array}{l}\text { Patient interviews/feedbacks from } \\
\text { patients using a preliminary } \\
\text { questionnaire }\end{array}$ & 10/2019 & two severely affected patients & $\begin{array}{l}\text { inconclusive, many items rated as } \\
\text { important }\end{array}$ \\
\hline Final online questionnaire & 10/2019-02/2020 & & s. Table 2 and Table 3 \\
\hline
\end{tabular}


related to the primary outcome and 20 provided all requested information.

The majority (17 of 21 respondents, $89 \%$ ) were female and median age was 40.5 years (IQR 31-51.5). Most responders $(n=18)$ underwent Roux-Y gastric bypass surgery, one participant sleeve gastrectomy and another one both (Table 2). The median postoperative interval was five years (IQR 2.8-7). Ten respondents (50\%) reported several hypoglycaemic episodes per week, five (25\%) reported daily episodes, and five (25\%) stated to have hypoglycaemic episodes at least once a month. Nine (45\%) reported to have a drug therapy for their postprandial hypoglycaemia of which six respondents specified their therapy (Table 2). One patient received a triple therapy.

Of all responding participants, 17 (77.3\%) deemed quality of life more relevant as primary outcome than the rate of hypoglycaemic episodes (5 participants; 22.7\%; Table 3). Of 21 responders, 19 (91.4\%) found taking a study medication for a period of four weeks acceptable, $15(71.3 \%)$ would accept three months, while only $12(52.1 \%)$ found six months or longer acceptable. Six patients (28.5\%) voted for a trial length of nine months or more (one free text answer opted for 18 months, s. Table 3).

\section{Discussion}

We used an evidence-based approach to design a clinical trial to test a novel treatment in patients with postprandial hypoglycaemia after bariatric surgery. This informed our decision to focus on quality of life as primary outcome, measured between four weeks and six months after randomization.

Neither our literature search in several databases, nor search for patient organizations provided us with the required information. Since we did not want to rely only on our perspectives as clinicians and clincial researchers we aimed to inform our decisons by involving patients,

Table 2 Baseline characteristics from participants of the online questionnaire

\begin{tabular}{|c|c|c|}
\hline Characteristic & Median (IQR; range) & n (\%) \\
\hline Total & & $29(100 \%)$ \\
\hline Age & $40.45($ IQR 31-51.5; 20-57) & \\
\hline \multicolumn{3}{|l|}{ Sex } \\
\hline male & & $2(6.9 \%)$ \\
\hline female & & $17(58.6 \%)$ \\
\hline no response & & $10(34.4 \%)$ \\
\hline \multicolumn{3}{|l|}{ Type of surgery } \\
\hline Roux-Y gastric bypass & & $18(62.1 \%)$ \\
\hline sleeve gastrectomy & & $1(3.4 \%)$ \\
\hline others & & $1(3.4 \%)$ \\
\hline no response & & $9(31.0 \%)$ \\
\hline Duration since bariatric surgery (years) & 5 (IQR 2.8-7; range 1-9) & \\
\hline \multicolumn{3}{|c|}{ Number of hypoglycemic episodes per week } \\
\hline daily & & $5(17.2 \%)$ \\
\hline not daily, but several days a week & & $10(34.5 \%)$ \\
\hline not weekly, but at least once a month & & $5(17.2 \%)$ \\
\hline no response & & $9(31.0 \%)$ \\
\hline \multicolumn{3}{|l|}{ Patients receiving off-label drug therapy } \\
\hline yes & & $9(31.0 \%)$ \\
\hline no & & $11(37.9 \%)$ \\
\hline no response & & $9(31.0 \%)$ \\
\hline \multicolumn{3}{|c|}{ Type of off-label therapy for postbariatric hypoglycemia } \\
\hline acarbose & & 2 \\
\hline liraglutide & & 2 \\
\hline empagliflozin & & 2 \\
\hline octreotide & & 1 \\
\hline onglyza & & 1 \\
\hline
\end{tabular}


Table 3 Online questionnaire results

\begin{tabular}{|c|c|}
\hline Question & n (\%) \\
\hline Total & $29(100 \%)$ \\
\hline \multicolumn{2}{|c|}{ What should a new treatment mainly improve? } \\
\hline Quality of life & 17 (59.2\%) \\
\hline Less hypoglycemic episodes & $5(18.2 \%)$ \\
\hline no response & $7(22.2 \%)$ \\
\hline \multicolumn{2}{|c|}{$\begin{array}{l}\text { For which trial length could you imagine to take a study } \\
\text { medication? }\end{array}$} \\
\hline two weeks & $2(9.5 \%)$ \\
\hline one month & $4(19.0 \%)$ \\
\hline three months & $3(14.3 \%)$ \\
\hline six months & $6(28.5 \%)$ \\
\hline nine months & $0(0 \%)$ \\
\hline one year & $5(23.8 \%)$ \\
\hline free text option: one and a half year & $1(4.7 \%)$ \\
\hline no response & $6(28.5 \%)$ \\
\hline
\end{tabular}

fully acknowledging that this simple approach cannot replace a sufficiently large and broad endeavour aiming to create a core outcome set, which would be most desireable. Instead, we used a pragmatic approach where we sought to involve patients as early as possible in the conception of our trial. We collected potential outcome candidates during clinical routine and research visits with affected patients. The discussion with two severely affected patients revealed that most of the items were valued as important hampering our approach to narrowing down potential candidates to a more practical number. We chose quality of life as one potential outcome parameter since this would cover many of the preliminary items and is a commonly used valid outcome parameter in clinical trials as well as part of the BARIACT COS [17].

We developed an online questionnaire that was easy to follow and quick to fill out. From a technical perspective the rate of hypoglycaemic episodes might be a most preferred primary outcome because of the objective and reliable measurement by continuous glucose monitoring, providing a clean measurement of physiological effects. However, this would disregard patient-relevant aspects such as inconveniences to take a drug, side effects and be not really patient important as it would not well reflect how patients "feel and function". Our study showed a clear patient preference of "quality of life" over a "reduced rate of hypoglycaemic episodes".

Most of the patients expressed a preference for an active trial length (i.e. intake of study medication) of four weeks or even longer, possibly indicating high feasibility and a high willingness of participants to adhere to a longer study period that might be required to show sustained effects of a treatment. Most of the respondents
(75\%) are strongly affected with hypoglycaemic episodes occurring either daily or several times per week, indicating an urgent need for treatment options. The number of patients that already receive an off-label drug therapy (45\%) and still notice a high frequency of hypoglycaemic episodes indicates not only the need for an effective treatment but also highlights problems related to offlabel prescribing, such as reimbursement aspects.

Several limitations need to be considered. First, our sample of patients was small and included only Germanspeaking participants from Switzerland, potentially limiting the generalizability of results. However, the sociodemographic and medical characteristices of the respondents of the questionnaire are very similar to the expected spectrum of patients with postbariatric hypoglycaemia with a female preponderance, younger age, bariatric surgery, and a typical postoperative interval $[5,6$, 32]. Second, our preselection of outcome parameters may have excluded other relevant outcomes which more extensive approaches (such as discrete choice experiments or Delphi rounds [33-35]) may reveal. Third, selection bias may have affected our findings. The exact response rate is unknown since we relied on the cooperation of other healthcare providers and that the questionnaire was fully anonymous and voluntary. However, strongly affected patients may have more likely responded and completed the questionnaire due to a higher motivation for finding an effective treatment. Fourth, our questionaire was online which may have introduced barriers to participate for certain patients, but in every centre patients were also offered paper-based forms to increase the number of responders as much as possible.

\section{Conclusions}

Quality of life seems to be the most important outcome for patients with postprandial hypoglycaemia after bariatric surgery. Using quality of life instead of rate of hypoglycaemia as the primary outcome in randomized clincal trials that test treatments for patients with this condition, may provide more useful and patient-relevant evidence to guide health care decisions.

\section{Appendix}

Search strategy for PubMed (date of last search 25 June 2020)

("Bariatric Surgery"[Mesh:NoExp] OR "Gastric Bypass"[Mesh] OR bariatric surg*[Tiab] OR Metabolic Surg*[tiab] OR "gastric bypass"[Tiab] OR "Roux-en-Y"[tiab] OR "Roux en Y"[tiab] OR "sleeve gastrectomy"[Tiab]) AND ("Postgastrectomy Syndromes"[Mesh] OR "latedumping" [Tiab] OR "Hypoglycemia"[Mesh:NoExp] OR "hypoglycemia"[Tiab] OR "hypoglycaemia"[tiab] OR "late dumping"[Tiab]) NOT ("animals" $[\mathrm{MeSH}$ Terms] NOT "humans"[MeSH Terms]) 


\section{Supplementary Information}

Supplementary information accompanies this paper at https://doi.org/10. 1186/s12874-020-01171-z.

Additional file 1: Supplementary file 1. Preliminary Questionnaire English final.

Additional file 2: Supplementary file 2. Short Questionnaire for Patient involvement with PBH V1.0.

\section{Abbreviations}

COS: core outcome set; IL-1: interleukin 1; PBH: postbariatric hypoglycaemia; SF-36: survey form-36; SGLT2: sodium-glucose like transporter 2

\section{Acknowledgements}

We are very grateful for the participation of patients in our study planning. We would also like to thank colleagues at the EbM-Network Meeting 2020 in Basel, Switzerland, for their critical inputs. Furthermore, we thank Dr. Hannah Ewald (University of Basel) for her assistance on the literature search and Dušan Tomić, MA, for critical discussions as well as Joe Monaghan for proofreading of the manuscript.

\section{Public dissemination}

Parts of this study were presented at the EbM-Network Meeting in February 2020 in Basel, Switzerland.

\section{Authors' contributions}

All authors (MH, MYD, LGH) were involved in the planning of the study and the development of the questionnaire. MH did patient interviews, performed the literature research, programmed the online questionnaire, did the statistical analysis and wrote the first draft of the manuscript. All authors $(\mathrm{MH}, \mathrm{MYD}, \mathrm{LGH})$ read, revised and approved the final manuscript.

\section{Funding}

This is an independent article and no funding was required.

\section{Availability of data and materials}

The datasets used and/or analyzed during the current study are available from the corresponding author on request.

\section{Ethics approval and consent to participate}

This study was approved (EKNZ Req-2019-00933) by the local ethics committee "Ethikkommission Nordwest- und Zentralschweiz", Basel, Switzerland. Participants were invited by email or directly in the outpatient clinic during routine visits to participate in the anonymous online questionnaire which at the beginning outlined the nature of the project, and described that participation was entirely voluntary. Consent to participate in the questionnaire was implied by its completion. No formal completion was required due to national regulations since participants were answering anonymously and no tracking was done.

\section{Consent for publication}

Not applicable.

\section{Competing interests}

The authors declare that they have no competing interests.

\section{Author details}

'Division of Endocrinology, Diabetology and Metabolism, University Hospital Basel, Petersgraben 4, 4053 Basel, Switzerland. ${ }^{2}$ Clinic of Endocrinology, Cantonal Hospital Olten, Basler Strasse 150, 4600 Olten, Switzerland. ${ }^{3}$ Basel Institute for Clinical Epidemiology and Biostatistics, Department of Clinical Research, University of Basel and University Hospital Basel, Basel, Switzerland. ${ }^{4}$ Meta-Research Innovation Center Berlin (METRIC-B), Berlin Institute of Health, Berlin, Germany. ${ }^{5}$ Meta-Research Innovation Center at Stanford (METRICS), Stanford University, Stanford, CA, USA.
Received: 8 August 2020 Accepted: 19 November 2020

Published online: 30 November 2020

\section{References}

1. Chang SH, Stoll CR, Song J, Varela JE, Eagon CJ, Colditz GA. The effectiveness and risks of bariatric surgery: an updated systematic review and meta-analysis, 2003-2012. JAMA Surg. 2014;149(3):275-87.

2. O'Brien PE, Hindle A, Brennan L, Skinner S, Burton P, Smith A, et al. Longterm outcomes after bariatric surgery: a systematic review and meta-analysis of weight loss at 10 or more years for all bariatric procedures and a singleCentre review of 20-year outcomes after adjustable gastric banding. Obes Surg. 2019;29(1):3-14.

3. Hu Z, Sun J, Li R, Wang Z, Ding H, Zhu T, et al. A comprehensive comparison of LRYGB and LSG in obese patients including the effects on QoL, comorbidities, weight loss, and complications: a systematic review and meta-analysis. Obes Surg. 2020;30(3):819-27.

4. Capristo E, Panunzi S, De Gaetano A, Spuntarelli V, Bellantone R, Giustacchin $P$, et al. Incidence of hypoglycemia after gastric bypass vs sleeve Gastrectomy: a randomized trial. J Clin Endocrinol Metab. 2018;103(6):213646.

5. Salehi M, Vella A, McLaughlin T, Patti ME. Hypoglycemia after gastric bypass surgery: current concepts and controversies. J Clin Endocrinol Metab. 2018; 103(8):2815-26.

6. Lee CJ, Clark JM, Schweitzer M, Magnuson T, Steele K, Koerner O, et al. Prevalence of and risk factors for hypoglycemic symptoms after gastric bypass and sleeve gastrectomy. Obesity (Silver Spring). 2015;23(5):1079-84.

7. Emous M, van den Broek M, Wijma R, de Heide LJM, Laskewitz A, van Dijk G, et al. Prevalence of hypoglycaemia in a random population after Roux-en-Y gastric bypass after a meal test. Endocr Connect. 2019;8(7):969-78.

8. Emous M, Wolffenbuttel BHR, Totté $E$, van Beek AP. The short- to mid-term symptom prevalence of dumping syndrome after primary gastric-bypass surgery and its impact on health-related quality of life. Surg Obes Relat Dis. 2017:13(9):1489-500.

9. Varma S, Clark JM, Schweitzer M, Magnuson T, Brown TT, Lee CJ. Weight regain in patients with symptoms of post-bariatric surgery hypoglycemia. Surg Obes Relat Dis. 2017;13(10):1728-34.

10. Rebelos E, Moriconi D, Scalese M, Denoth F, Molinaro S, Siciliano V, et al. Impact of Postprandial Hypoglycemia on Weight Loss After Bariatric Surgery. Obes Surg. 2020;30:2266-73.

11. Mitchell JE, Crosby R, de Zwaan M, Engel S, Roerig J, Steffen K, et al. Possible risk factors for increased suicide following bariatric surgery. Obesity (Silver Spring). 2013;21(4):665-72.

12. Adams TD, Mehta TS, Davidson LE, Hunt SC. All-cause and cause-specific mortality associated with bariatric surgery: a review. Curr Atheroscler Rep. 2015;17(12):74.

13. Gribsholt SB, Thomsen RW, Svensson E, Richelsen B. Overall and causespecific mortality after roux-en-Y gastric bypass surgery: a nationwide cohort study. Surg Obes Relat Dis. 2017:13(4):581-7.

14. Lee CJ, Wood GC, Lazo M, Brown T, Clark JM, Still C, et al. Risk of postgastric bypass surgery hypoglycemia in nondiabetic individuals: a single center experience. Obesity (Silver Spring). 2016;24(6):1342-8.

15. Hepprich M, Wiedemann SJ, Schelker BL, Trinh B, Stärkle A, Geigges M, et al. Postprandial hypoglycemia in patients after gastric bypass surgery is mediated by glucose-induced IL-1ß. Cell Metab. 2020;31(4):699-709.e5.

16. Williamson PR, Altman DG, Blazeby JM, Clarke M, Devane D, Gargon E, et al. Developing core outcome sets for clinical trials: issues to consider. Trials. 2012:13:132

17. Coulman KD, Hopkins J, Brookes ST, Chalmers K, Main B, Owen-Smith A, et al. A Core outcome set for the benefits and adverse events of bariatric and metabolic surgery: the BARIACT project. PLoS Med. 2016;13(11): e1002187.

18. Nielsen JB, Abild CB, Pedersen AM, Pedersen SB, Richelsen B. Continuous glucose monitoring after gastric bypass to evaluate the glucose variability after a low-carbohydrate diet and to determine hypoglycemia. Obes Surg. 2016;26(9):2111-8.

19. Lembo E, Lupoli R, Ciciola P, Creanza A, Silvestri E, Saldalamacchia G, et al. Implementation of Low Glycemic Index Diet Together with Cornstarch in Post-Gastric Bypass Hypoglycemia: Two Case Reports. Nutrients. 2018;10(6): 670.

20. Øhrstrøm CC, Worm D, Højager A, Andersen D, Holst JJ, Kielgast UL, et al. Postprandial hypoglycaemia after roux-en-Y gastric bypass and the effects 
of acarbose, sitagliptin, verapamil, liraglutide and pasireotide. Diabetes Obes Metab. 2019;21(9):2142-51.

21. Øhrstrøm CC, Hansen DL, Kielgast UL, Hartmann B, Holst JJ, Worm D. A low dose of Pasireotide prevents hypoglycemia in roux-en-Y gastric bypassoperated individuals. Obes Surg. 2020;30(4):1605-10.

22. Salehi M, Gastaldelli A, D'Alessio DA. Blockade of glucagon-like peptide 1 receptor corrects postprandial hypoglycemia after gastric bypass. Gastroenterology. 2014;146(3):669-80 e2.

23. Tack J, Aberle J, Arts J, Laville M, Oppert JM, Bender G, et al. Safety and efficacy of pasireotide in dumping syndrome-results from a phase 2 , multicentre study. Aliment Pharmacol Ther. 2018:47(12):1661-72.

24. Kefurt R, Langer FB, Schindler K, Shakeri-Leidenmuhler S, Ludvik B, Prager G. Hypoglycemia after roux-en-Y gastric bypass: detection rates of continuous glucose monitoring (CGM) versus mixed meal test. Surg Obes Relat Dis. 2015:11(3):564-9.

25. Gasser M, Meier C, Herren S, Aubry E, Steffen R, Stanga Z. Is testing for postprandial hyperinsulinemic hypoglycemia after gastric bypass necessary? Clin Nutr. 2019;38(1):444-9

26. Sessa L, Guidone C, Gallucci P, Capristo E, Mingrone G, Raffaelli M. Effect of single anastomosis duodenal-ileal bypass with sleeve gastrectomy on glucose tolerance test: comparison with other bariatric procedures. Surg Obes Relat Dis. 2019;15(7):1091-7.

27. Chiarotto A, Ostelo RW, Turk DC, Buchbinder R, Boers M. Core outcome sets for research and clinical practice. Braz J Phys Ther. 2017;21(2):77-84.

28. M H. Limesurvey Questionnaire: Fragebogen für Patientenbeteiligung in der Forschung zur Behandlung postprandialer Unterzuckerungen 2019 [Available from: https://dekmed.limequery.com/145331?newtest=Y〈=de.

29. Schweizerische Adipositas-Stiftung SAPS (Swiss Obesity Foundation) [Available from: https://saps.ch/de/angebote/selbsthilfegruppen. Accessed 15 June 2020.

30. SHG Bariatrische Chirurgie (Swiss Bariatric Surgery Self-Help Network) [Available from: http://neu.shg-bern.ch/index.php/BoardList/. Accessed 15 June 2020.

31. Bottomley A, Reijneveld JC, Koller M, Flechtner H, Tomaszewski KA, Greimel $\mathrm{E}$, et al. Current state of quality of life and patient-reported outcomes research. Eur J Cancer. 2019;121:55-63.

32. Nannipieri M, Belligoli A, Guarino D, Busetto L, Moriconi D, Fabris R, et al, Risk factors for spontaneously self-reported postprandial hypoglycemia after bariatric surgery. J Clin Endocrinol Metab. 2016;101(10):3600-7.

33. Stamuli E, Torgerson D, Northgraves M, Ronaldson S, Cherry L. Identifying the primary outcome for a randomised controlled trial in rheumatoid arthritis: the role of a discrete choice experiment. J Foot Ankle Res. 2017;10: 57.

34. Rankin A, Cadogan CA, In Ryan C, Clyne B, Smith SM, Hughes CM. Core outcome set for trials aimed at improving the appropriateness of Polypharmacy in older people in primary care. J Am Geriatr Soc. 2018;66(6): 1206-12.

35. Prinsen CA, Vohra S, Rose MR, King-Jones S, Ishaque S, Bhaloo Z, et al. Core Outcome Measures in Effectiveness Trials (COMET) initiative: protocol for an international Delphi study to achieve consensus on how to select outcome measurement instruments for outcomes included in a 'core outcome set'. Trials. 2014;15:247.

\section{Publisher's Note}

Springer Nature remains neutral with regard to jurisdictional claims in published maps and institutional affiliations.

\section{Ready to submit your research? Choose BMC and benefit from}

- fast, convenient online submission

- thorough peer review by experienced researchers in your field

- rapid publication on acceptance

- support for research data, including large and complex data types

- gold Open Access which fosters wider collaboration and increased citations

- maximum visibility for your research: over $100 \mathrm{M}$ website views per year

At $\mathrm{BMC}$, research is always in progress.

Learn more biomedcentral.com/submissions 